\title{
A Comparative Study of Performance of Different Control Architectures for Reactor System
}

\author{
Gagandeep Kaur \\ Department of Electrical and \\ Instrumentation Engineering \\ Thapar University, Patiala, \\ 147004, Punjab
}

\author{
Rupinder Kaur \\ Department of Electrical and \\ Instrumentation Engineering \\ Thapar University, Patiala, \\ 147004, Punjab
}

\begin{abstract}
A chemical reactor is one of the primary components of a chemical industry used for containing exothermic and endothermic chemical reactions. It is used for the chemical reactions which have heating and cooling of one or more than one chemical. There is a need to control the temperature in chemical reactor. In this research paper, a comparative study of performance of different controllers is performed whose primary aim is to control the outlet temperature of the reactor system to a desired value. Time domain and frequency domain analysis of different controllers are analysed.
\end{abstract}

\section{Keywords}

Chemical reactor, Controller, Time domain

\section{INTRODUCTION}

A chemical reactor is one of the primary components of a chemical industry used for containing exothermic and endothermic chemical reactions. It is used for the chemical reactions which have heating and cooling of one or more than one chemical. There are different kinds of reactors such as

\section{Continuous Stirred Tank Reactor (CSTR) \\ 2. Plug Flow Reactor (PFR) \\ 3. Semi Batch Reactor \\ 4. Catalytic Reactor}

The heating and cooling of the chemical reactor has to be controlled. The temperature of the chemical reactor has to be controlled to a desired set point. For controlling purpose, a controller is used. The objective of the controller is to control the temperature of the outgoing fluid to a desired set point. There are many type of controller available in the market, but the most widely used controller in the industry is Proportional-Integral-Derivative (PID) controller. It is estimated that around $90 \%$ process control loops employ PID controller and quite often the derivative gain is set to zero [4] or the integral gain is set to zero according to the control requirement. With its three-term functionality covering treatment to both transient state and steady state responses, proportional-integral-derivative (PID) control offers the simplest yet the most efficient solution to many real-world control problems [1]. The proportional action adjusts controller output according to the size of the error, the integral action eliminates the steady state offset and the future is anticipated via derivative action. Since the invention of PID control in 1910, and the Ziegler-Nichols's tuning methods in 1942 [2], the popularity of PID control in industry has grown tremendously. The procedure for selecting the values of the controller is called tuning and the adjustable parameters of the controller are termed as tuning constant. The Zeigler-Nichols settings usually experience excessive overshoot and this method cannot be used to tune plants that have relatively normalized time delay [3]. The parameter setting of the PID controller is based on the plant's behavior so before tuning the PID controller the designer needs all the relevant information of the plant as well as the process model. PID controllers are designed for linear systems and the presence of non linearity which is very common in the process industry limits their performance and severely effects the controlling action [5].

\section{CASE STUDY}

Figure 1 shows the schematic diagram of a reactor system widely used in process industry.

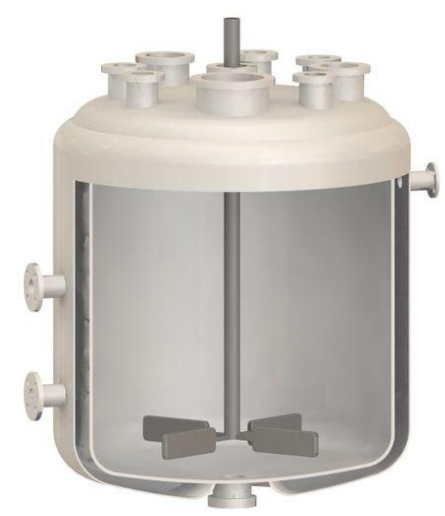

Figure 1: Schematic diagram of reactor system

In this paper, the temperature of the CSTR is controlled using two different controllers.

1. Feedback controller

2. Feedback plus feed-forward controller

In feedback controller, PID controller is used which is tuned using Zeigler-Nichols tuning rule.

\section{LITREATURE REVIEW}

G K I Mann et.al, analyzed different time domain based design and analysis of PID tuning for FOPTD process. The proposed PID tuning rule is capable of handling actuator saturation and can handle process and controller non linearity in an effective manner [13] 
P Cominos et.al has reviewed recent tuning methods and design specification of PID controller [12].

Carl Knopse has given a clear review of the PID controller and tuning methods [4].

\section{PROBLEM FORMULATION}

This section gives the overview of the problem discussed in the paper. Figure 2 shows the feedback control loop implemented in CSTR system to control the temperature of outgoing fluid.

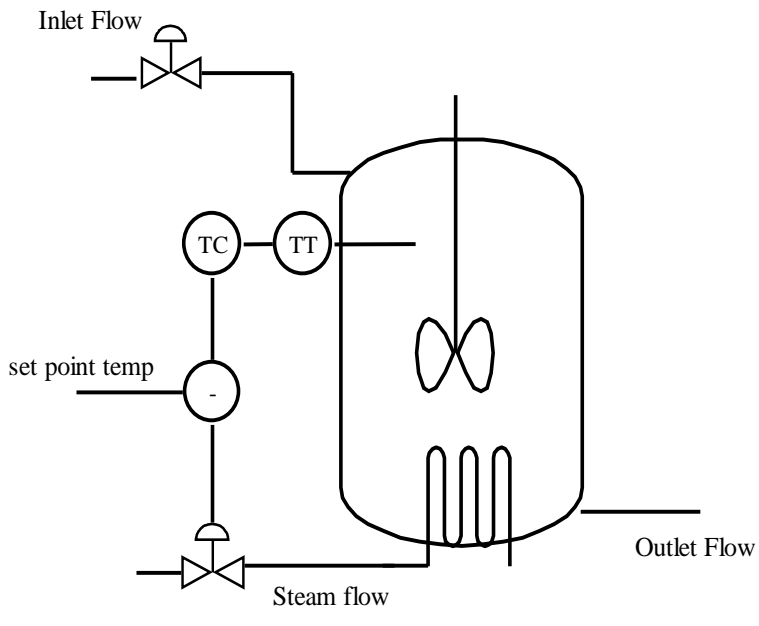

\section{Figure 2: Feedback control in CSTR}

The experimental data [9] for the reactor are summarized below

Transfer function of flow sensor: $\frac{0.1}{5 s+1}$

Transfer function for pressure disturbance: $\frac{1}{20 s+1}$

Transfer function for flow disturbance: $\frac{2}{20 s+1}$

\section{Feedback Control}

Figure 3 shows the block diagram approach of feedback control of CSTR

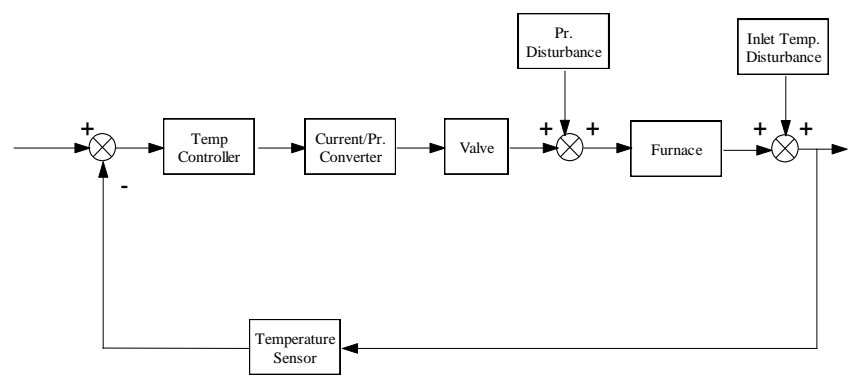

Figure 3: Block Diagram Approach of Feedback Control

To control the temperature feedback control is employed and PID controller is used as the controlling element. The general block diagram approach of feedback controller is shown below.

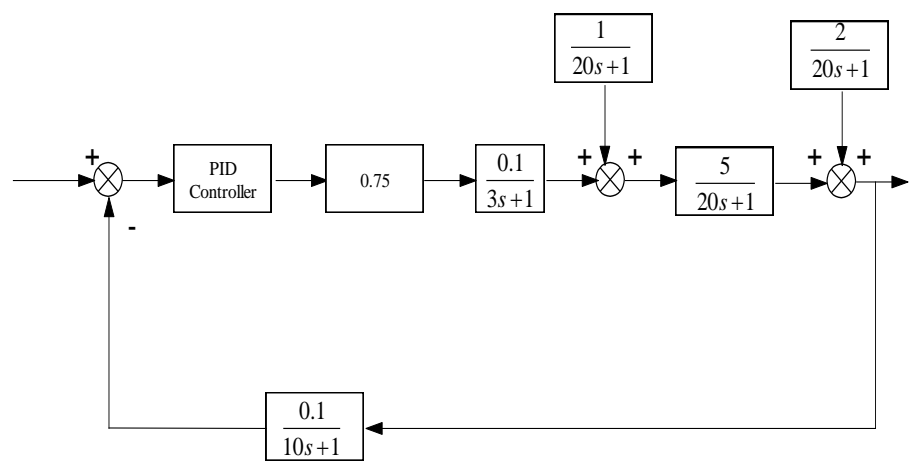

Figure 4: Transfer Function Approach of Feedback Control

Figure 3 shows the general block diagram of the feedback system where as figure 4 shows the transfer function approach of block diagram of the proposed control system.

$\mathrm{Eq}(1)$ shows the time domain equation of ideal PID controller.

The general form of PID controller is

$$
\begin{aligned}
& u(t)=K_{c}\left(e(t)+\frac{1}{\tau_{i}} \int_{0}^{t} e(t) d t+\tau_{d} \frac{d e(t)}{d t}\right) \\
& u(s)=K_{c}\left(1+\frac{1}{\tau_{i} s}+\tau_{d} s\right) e(s) \\
& u(s)=K_{c}\left(\frac{1+\tau_{i} s+\tau_{i} \tau_{d} s^{2}}{\tau_{i} s}\right) e(s)
\end{aligned}
$$

The real PID controller is

$u(s)=K_{c}\left(\frac{1+\tau_{i} s}{\tau_{i} s}\right)\left(\frac{1+\tau_{d} s}{1+\alpha \tau_{d} s}\right) e(s)$

The PID controller is traditionally suitable for second and lower order systems. It can also be used for higher order plants with dominant second order behavior. The Ziegler-Nichols (Z-N) methods rely on open-loop step response or closed-loop frequency response tests. A PID controller is tuned according to a table based on the process response test. According to Zeigler-Nichols frequency response tuning criteria

$K_{p}=0.6 K_{c}$

$\tau_{i}=0.5 T$

$\tau_{d}=0.125 T$

The architecture of PID controller is shown below in figure 5. 


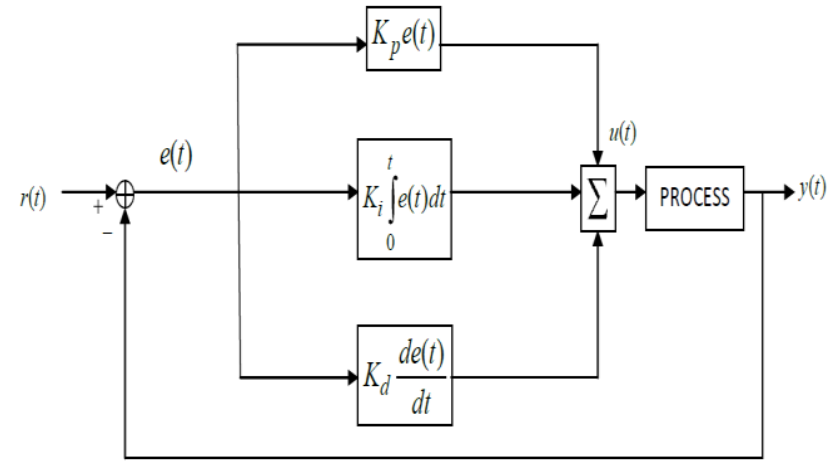

Figure 5: Architecture of PID controller

The following diagram shows the selection of different terms for the PID controller.



Figure 6: Selection of different terms in PID controller 4.1 Feedback and Feed forward Controller

Due to inherent disadvantages of feedback controller, feed forward controller is used. Feed forward controller, estimates the probable error criteria and tries to remove the error, before it occurs.

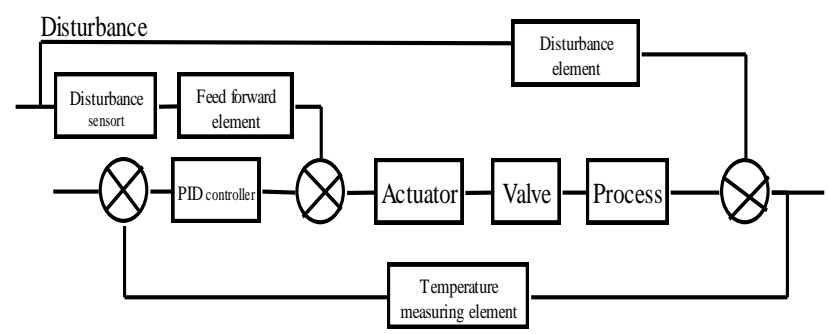

Figure 7: Architecture of feedback plus feed forward control
In section 5 , the unit step response of the feedback and feed forward architecture is studied and the performance of the controller is analysed.

\section{RESULTS \& DISCUSSIONS}

Figure 7 shows the unit step response of reactor system with PID controller, which controls the outgoing temperature of the reactor.



Figure 8: Unit step response of system with PID controller Figure 8 shows the unit step response of the reactor system with feedback plus feed forward controller. The feed forward controller is used in conjunction with the feedback controller.

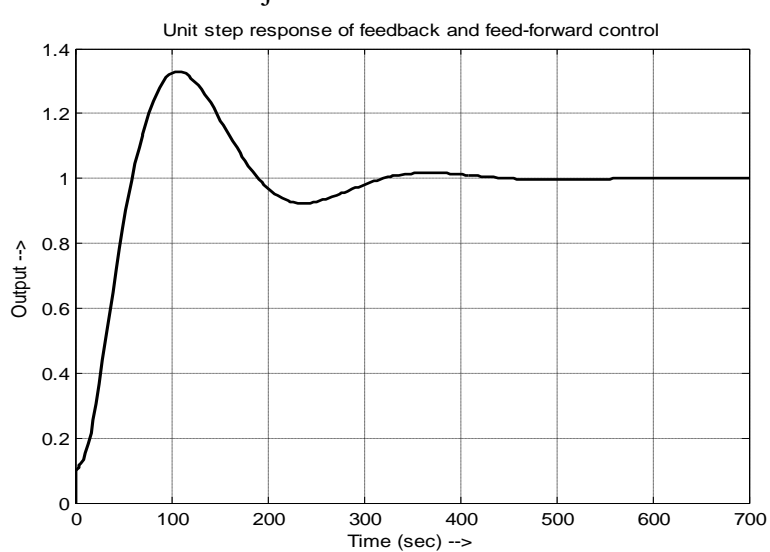

Figure 9: Unit step response of feedback plus feed forward controller

Peak Overshoot: $\% M_{p}=\frac{c\left(t_{p}\right)-c(\infty)}{c(\infty)} * 100 \%$

Settling Time: It is the time required for the response to reach and stay within a specified tolerance band of its final value. The tolerance band is taken randomly as $5 \%$.

Peak Time: Peak time is defined as the time required reaching the peak of the unit step response.

Table 1 shows the comparative overview of different transient domain parameters like peak overshoot, peak time and settling time of feedback and feedback plus feed forward controller. 
Table 1: Transient domain parameters of controllers

\begin{tabular}{|l|l|l|l|}
\hline & $M_{p}$ & $t_{p}$ & $t_{s}$ \\
\hline Feedback & $39.4 \%$ & $100.27 \mathrm{sec}$ & $364.01 \mathrm{sec}$ \\
\hline $\begin{array}{l}\text { Feedback } \\
\text { plus feed } \\
\text { forward }\end{array}$ & $35.83 \%$ & $95.68 \mathrm{sec}$ & $345.3 \mathrm{sec}$ \\
\hline
\end{tabular}

Table 2 shows the performance indices of the different controllers.

$$
\begin{aligned}
& I A E=\int_{0}^{\infty}|e(t)| d t \\
& I S E=\int_{0}^{\infty} e^{2}(t) d t
\end{aligned}
$$

Table 2: Error criteria of different controllers

\begin{tabular}{|l|l|l|}
\hline & IAE & ISE \\
\hline Feedback & 74.97 & 36.9 \\
\hline $\begin{array}{l}\text { Feedback } \\
\text { plus feed } \\
\text { forward }\end{array}$ & 71.58 & 34.89 \\
\hline
\end{tabular}

From the above discussions, it is clear that feed forward plus feedback controller is a better controller, rather than feedback controller, when temperature control of reactor system is concerned.

\section{CONCLUSION}

This paper, takes a case study of chemical reactor and tries to control the outgoing temperature of chemical reactor to a desired temperature. First the mathematical model of the system is developed and then feedback and feed forward controller is implemented to obtain the control objective. It is seen from results that the feedback plus feed forward controller is best as compared to feedback controller. There is a lot of future scope of this area, where intelligent control can be implemented.

\section{REFERENCES}

[1] Ang, Kiam Heong, Chong, Gregory and Li Yun, "PID control system analysis, design, and technology," Trans. IEEE control system and technology, Vol. 13, No.4, 559$576,(2005)$
[2]

Zeigler, J.G. and Nichols, N.B., "Optimum setting for automatic controllers," Trans. ASME, Vol. 64, 759-768, (1942).

[3] Mann, G., K., I., Hu, B., G., and Gosine, R.G., "Time domain based design and analysis of new PID tuning rules," Proc. IEEE- Control theory application, Vol 148, no. 3, 251-261, (2001).

[4] Knopse, Carl, "PID control," Guest editor, Introduction to special edition, IEEE control system, 30-31 (2006)

[5] Erenoglu, Isin, Eksin, Ibrahim, Yesil, Engin, and Guzelkaya, Mujde, "An intelligent hybrid fuzzy PID controller," Proc. $20^{\text {th }}$ European conf. on modeling and simulation, (2006).

[6] Astrom, K.J., Hang, C. C., Persson, P., and Ho, W.K., "Towards intelligent PID control," Automatica, Vol. 28, No.1, 9, (1992).

[7] Astrom, K.J. and Hagguland, T., "The future PID control," Control eng. Practice (9), Elsevier, 1163-1175, (2001).

[8] Mizumoto, M., "Realization of PID control by fuzzy control methods," Proc. IEEE Int. Conf. of fuzzy systems. 709-715, (1992).

[9] Gopal, M., "Control systems principles and design," Tata Mcgraw hill Publishers, New Delhi, (2007)

[10] Nagrath, I., J. and Gopal, M., "Control system engineering," Newage International Publishers, New Delhi, 278-292 (2007)

[11] Vaishnav, S.R., and Khan, Z.J., "Design of PID and fuzzy logic controller for higher order system," Int. Conf. on control and automation (ICCA), China, 1469-1472, (2007)

[12] Cominos, P., and Murno., P., "PID controllers: recent tuning methods and design to specification," IEEE. Proc. Control theory and application, 46-53, (2002)

[13] Manish Kumar, and Devendra P Garg, "Intelligent Learning Of Fuzzy Logic Controllers Via Neural Network And Genetic Algorithm," Proceedings of 2004 JUSFA 2004 Japan - USA Symposium on Flexible Automation Denver, pp. 1-8, July 2004.

[14] Subhransu Padhee, Yaduvir Singh, Yuvraj B Khare, "Internal model based PID control of shell and tube heat exchanger system," Proc. 2011 IEEE Student's Technology Symposium, Jan 2011, pp. 297 - 30 